\title{
Correspondence
}

\section{Vasoactivity of the major intracranial arteries in the newborn child}

Sir,

I read with interest the paper of Drayton and Skidmore, showing vasoactivity of the cerebral circulation in preterm infants. ${ }^{1}$ I note in their study population four infants had developed intraventricular haemorrhage and five infants had signs of periventricular leucomalacia. Volpe has shown with positron emission tomography that intracranial haemorrhage has a dramatic effect on regional cerebral blood flow, ${ }^{2}$ and it is well recognised that intracranial haemorrhage can cause arterial spasm. Previous studies have shown that intraventricular haemorrhage occurs soon after birth in many infants. ${ }^{3}{ }^{4}$ It is possible that the changes in cerebral vasoactivity that Drayton and Skidmore describe in their paper are secondary to intraventricular haemorrhage. If the results of the nine infants with either periventricular haemorrhage or leucomalacia are removed from the preterm study population, do the results reported still pertain? If so this makes a much more interesting paper.

\section{References}

1 Drayton MR, Skidmore R. Vasoactivity of the major intracranial arteries in newborn infants. Arch Dis Child 1987;62:236-40.

2 Volpe JJ, Herscovitch P, Perlman JM, Raichle ME. Positron emission tomography in the newborn: Extensive impairment of regional cerebral blood flow with intraventricular haemorrhage and haemorrhagic intracerebral involvement. Paediatrics 1983;72:589-601.

${ }^{3}$ Ch de Crespigny L. Mackay R, Murton LJ, Roy RND, Robinson PH. Timing of neonatal cerebroventricular haemorrhage with ultrasound. Arch Dis Child 1982;57:231-3.

4 Beverley DW, Chance GW, Coates CF. Intraventricular haemorrhage-timing of occurrence and relationship to perinatal events. Br J Obstet Gynaecol 1984;91:1007-13.

\section{BEVERLEY Clarendon Wing, The General Infirmary at Belmont Grove, Leeds LS2 9NS}

\section{Dr Drayton comments:}

Dr Beverley enquires whether the changes in cerebral artery calibre reported in March 1987 could be secondary to intracranial pathology. The nine infants with abnormal real-time ultrasound scans were heterogenous for both type and timing of abnormal appearance. When these infants are removed from the analysis the same results pertain. In the remaining 21 infants, mean ACA velocity increased from 2.5 to $5.5 \mathrm{~cm} / \mathrm{second}$; mean MCA velocity increased from 4.8 to $8.8 \mathrm{~cm} /$ second. There was no significant change in head and neck perfusion and the mean standardised flow:velocity ratio decreased from 19.5 to $8 \cdot 5$.

These changes are clearly not the result of intracranial haemorrhage, but the implied early vasodilation is more likely to be a factor in its genesis.

M R DraytoN
Department of Neonatal Medicine,
Southmead General Hospital,
Westbury-On-Trym,
Bristol BS10 5NB

\section{Cardiovascular effects of tolazoline and ranitidine}

\section{Sir,}

Tolazoline, used in standard doses, reliably produces gastric erosions and bleeding. The article by Bush et al suggests that ranitidine should not be used to counteract this undesirable side effect. For the past seven years we have used $2 \cdot 8 \%$ sodium bicarbonate stomach washouts to reduce bleeding from erosions caused by tolazoline. In full term infants we use $10 \mathrm{ml}$ of this solution to wash out the stomach every two hours until the bleeding stops, and subsequently, at longer intervals. Usually 1-2 ml remains in the stomach each time. We have had no problems with hypernatraemia to date, although most infants develop a mild alkalosis. Bleeding usually stops or is greatly diminished within 24 hours.

\section{Reference}

' Bush A. Busst CM, Knight WB, Shincbourne EA. Cardiovascular effects of tolazoline and ranitidine. Arch Dis Child 1987:62:241-6.

\section{E M KIELY \\ Hospital for Sick Children, Great Ormond Street, London WCIN $3 J H$}

\section{Management of asthma in schools}

Sir,

Hill, Britten, and Tattersfield's views on the management of asthma in schools and Dr Couriel's letter, suggesting that the school medical service could help to identify the underdiagnosed and undertreated, ${ }^{1}{ }^{2}$ spur me to enlighten them on the school doctor's role. Every mother seen in the small group of schools where I work is asked if their child 